\title{
DETERMINING ADEQUATE VIBRATION FREQUENCY, AMPLITUDE, AND TIME FOR MECHANICAL HARVESTING OF FRESH MANDARINS
}

\author{
C. Ortiz, A. Torregrosa
}

\begin{abstract}
Mechanical citrus harvesting systems in Spain can solve the problem of the high costs of manual harvesting. Previous results, without the use of abscission agents, have shown the effectiveness of trunk and limb shakers for mechanical citrus harvesting. It is crucial to define the adequate vibration time to achieve an acceptable removal percentage because a higher vibration time could render the operation economically unviable. To address mechanical citrus harvesting, it is also necessary to determine the vibration conditions (amplitude, frequency, and duration) to ensure maximum removal efficiency. The objective of this research is to determine the optimal combination of vibration frequency, amplitude, and duration that will ensure maximum removal efficiency in mechanical citrus harvesting. 'Marisol' and 'Orogrande' mandarin trees were tested and harvested with a commercial trunk shaker. The 'Marisol'trees were shaken at a vibration of $15 \mathrm{~Hz}$ for $5 \mathrm{~s}$ with a $0.030 \mathrm{~m}$ displacement. The 'Orogrande' trees were shaken at 15 and $20 \mathrm{~Hz}$ frequencies with two shakes, the first lasting $5 \mathrm{~s}$ and the second lasting $2 \mathrm{~s}, 3$ to $4 \mathrm{~s}$ after the first shake, with a $0.030 \mathrm{~m}$ displacement. Due to the low trunk height of orchard trees in the Valencia region, it is impossible to study intermediate and high amplitudes with a commercial olive trunk shaker. To solve this limitation, a laboratory unidirectional vibratory device was used to shake the branches at a vibration frequency of 4.6 to $18.1 \mathrm{~Hz}$ and a vibration amplitude modified from 0.06 to $0.18 \mathrm{~m}$. The field and laboratory results show that the mechanical citrus removal percentage exhibits a logarithmic behavior with time. The laboratory test shows that high-amplitude and intermediate vibration frequencies in the branches achieve adequate removal percentages. Lengthening the shaking time and repeating the shaking process do not increase the removal efficiency. In the field test, almost all the detached fruit fell in the first 2 to $3 \mathrm{~s}$ of shaking. It was evident that two shakes were not necessary to obtain an acceptable removal percentage. The results found in the laboratory indicate the possibility of reducing the frequencies and increasing the amplitudes to achieve an optimal mechanical citrus harvest. In the fresh market for citrus from the Mediterranean region, with very low citrus trunk heights, mechanical harvesting equipment can be adapted to achieve high vibration amplitude and intermediate vibration frequencies in the branches.
\end{abstract}

Keywords. Citrus, Mechanical harvest, Trunk shaker, Vibration duration.

$\mathrm{T}$ he high costs of manual citrus harvesting compel the use of mechanical harvesting systems (Brown, 2005). Florida growers harvest most of their production for processing into juice. Within this framework, mechanical harvesting systems are emerging for commercial use. These systems can be used in various compatible groves by the juice industry. Cost saving of $25 \%$ to $75 \%$ could be achieved depending on the type of grove and the appropriate harvesting system.

The economic analysis of Reig-Martinez and PicazoTadeo (2004) highlighted the inefficiency of some current citrus crop farming practices in Valencia (Spain) compared with the adoption of available technologies using the optimal input mix according to the current input prices. In the Spanish Mediterranean area, the orchard architecture (small

Submitted for review in July 2012 as manuscript number PM 9838; approved for publication by the Power \& Machinery Division of ASABE in January 2013.

The authors are Coral Ortiz, Associate Professor, and Antonio Torregrosa, Professor, Department of Agricultural Engineering, Universitat Politècnica de València, Valencia, Spain. Corresponding author: Coral Ortiz, Camino de Vera s/n, Universitat Politècnica de València, 46022 Valencia, Spain; phone: 0034-963877295; e-mail: cortiz@dmta.upv.es. size of the orchards and small planting distance) precludes the use of canopy shakers to the extent found in other countries (Peterson, 1998).

Hedden et al. (1988) evaluated the effectiveness of four trunk-shaking patterns (two linear and two multidirectional, with and without abscission chemicals). They concluded that trunk growth was not affected by shaking and that the most vigorous linear shaking pattern provided superior harvesting efficiency.

Whitney et al. (2000) tested orange removal efficiency with and without abscission chemicals. Without abscission agents, oranges were removed by trunk shakers. They maintained that lower frequencies $(6$ to $10 \mathrm{~Hz})$ with $0.05 \mathrm{~m}$ amplitude have a $15 \%$ higher fruit removal than higher frequencies $(15$ to $18 \mathrm{~Hz})$ with lower displacement $(0.03 \mathrm{~m})$.

Most of the citrus production in Spain is aimed at the fresh market. Damage to citrus fruits during collection restricts mechanical harvesting. However, shock-absorbing surfaces have proved to be useful to reduce the damage to citrus destined for the fresh market (Ortiz et al., 2011). Previous tests performed in Spanish citrus orchards without the use of abscission agents have shown the effectiveness of trunk and limb shakers for orange, mandarin, and lemon mechanical harvesting (Torregrosa et al., 2009; Torregrosa et 
al., 2010). With a trunk shaker that produces a displacement of approximately $0.025 \mathrm{~m}$ and frequencies between 10 and $21 \mathrm{~Hz}$, field results showed that $15 \mathrm{~Hz}$ was an adequate frequency to prevent excessive defoliation while obtaining a high fruit removal percentage. Almost all the fruit fell within the first $5 \mathrm{~s}$ of shaking, and two shakes of 3 to $5 \mathrm{~s}$ each were enough to obtain an acceptable removal percentage (approximately 72\%). For 'Salustiana' oranges, three to four successive shakes per tree using three different shaking times (3.2, 4.2, and $5.2 \mathrm{~s})$ were evaluated. The removal percentages increased with the total shaking time, but the differences were not statistically significant at $5 \%$. Considering the percentage of the total fruits removed, the authors concluded that the first shake removed the highest proportion of fruits, at $69 \%$; the second shake detached $17 \%$ more fruit, and three and four shakes removed only the remaining $9 \%$ and $5 \%$, respectively.

García (2011) studied 35 variables that may influence the profitability of trunk shaker harvesting, and they selected the five most important variables for fresh market citrus. Profitability limits were calculated according to the selected variables. With values higher than 30 trees $^{-1}, 63 \mathrm{~kg}$ tree ${ }^{-1}$, $67 \%$ fruit removal, 1.2 ha orchard size, and $14 \%$ noncommercial fruit, a harvesting operation will have a high probability of being profitable. With the average values of the Valencia region for the other factors, a removal percentage higher than $67 \%$ could be enough to make trunk shaker harvesting profitable.

When harvesting with a trunk shaker, it is crucial to define the vibration time adequate to achieve an acceptable removal percentage because a longer vibration time could render the operation economically unviable and defoliation unacceptable. Reducing the vibrating time reduces the harvesting time and fuel consumption and could make mechanical harvest defoliation acceptable. According to $\mathrm{Li}$ and Syvertsen (2005), healthy, well-managed citrus trees are capable of tolerating the defoliation and other injuries caused by a trunk shaker. However, more severe damage could appear when trees are shaken for an excessive duration. They propose limiting the shaking time to less than $10 \mathrm{~s}$ when vibrating with a maximum trunk displacement of $6.5 \mathrm{~cm}$ and a frequency of $4 \mathrm{~Hz}$.

Mateev and Kostadinov (2004) established a probabilistic model describing vibratory fruit removal under different specified harvest conditions. The vibratory impact on a fruitbearing tree, the relative quantity of the non-detached fruit from the tree, and the probability of insufficient harvest duration are coincident and decrease exponentially when the vibratory duration increases.

He et al. (2012) studied the fruit removal efficiency of a hydraulically powered limb shaker for sweet cherry harvest. They found that the optimal operational conditions were 18 $\mathrm{Hz}$ shaking frequency and $5 \mathrm{~s}$ duration. They observed an increase in the removal percentage and a decrease in the energy efficiency (considered as the removal rate for every $\mathrm{kJ}$ of energy consumption) related to the cumulative time.

Blanco-Roldan et al. (2009) explained how, in Spanish oil olive trunk shaking, it is common practice to lengthen the shaking times and repeat the shaking process in an attempt to remove a greatest amount of fruit. However, these practices may reduce the life of the equipment and increase the risk of damage to the tree trunk. They studied three harvesting times and the application of one continuous vibration or two consecutive vibrations. Analysis of the images of the removal process showed the importance of shaking time and the number of vibration repetitions on fruit removal. Two consecutive vibrations removed more fruit than one continuous vibration only during the initial and middle stages of the harvesting season. At the end of harvest, it was more effective to use one continuous vibration. Moreover, they found that the average time needed to achieve a high removal percentage at the end of the harvesting season decreased from 13.3 to $2.1 \mathrm{~s}$.

Roka et al. (2005) addressed the vibration duration with a trunk shaker when harvesting late-season 'Valencia' oranges. The shaking time decreased from 10 to $4 \mathrm{~s}$ per tree. The operator varied the frequency, changing the throttle intermittently, creating a whipping action important to achieve a good fruit removal percentage. With the more aggressive vibrations, the yield reductions in the next year's crop were significantly higher compared with hand-picking. Moreover, harvesting with $10 \mathrm{~s}$ shake duration produced a greater next-year yield decrease than harvesting with $4 \mathrm{~s}$ shake duration.

As in mechanical trunk shaking for oil olives, it is natural to think that lengthening the citrus shaking time and repeating the shaking process will increase the removal percentage. However, the efficiency of these practices, apart from reducing the life of the equipment and increasing the risk of damage to the tree, is uncertain. In addition, the type of trunk shakers used in olive harvesting, with low amplitude and high frequency, may not be adequate for mechanical citrus harvesting. Due to the low trunk height of citrus trees cultivated in the Valencia region, a commercial trunk shaker is unable to operate without high amplitudes. To address mechanical citrus harvesting, it is necessary to determine the vibration conditions (amplitude, frequency, and duration) that will ensure maximum removal efficiency.

The objective of this research is to relate the citrus removal percentage to the vibration time according to frequency and amplitude and to assess the optimal combination of vibration frequency, amplitude, and duration that will ensure maximum removal efficiency in mechanical fresh citrus harvesting.

\section{Materials ANd Methods}

Two different experiments were performed: a field experiment and a laboratory experiment.

\section{FIELD EXPERIMENT}

Healthy and well-managed 'Marisol' and 'Orogrande' mandarin trees (Citrus reticulata, Blanco) grafted on Carrizo citrange [C. sinensis (L.) Osb. $\times$ Poncirus trifoliata (L.) Raf.] were tested. The 'Marisol' trees (20 years old), with $3 \mathrm{~m}$ height, $0.90 \mathrm{~m}$ trunk height, and $0.19 \mathrm{~m}$ trunk diameter, were drip irrigated in a 6 to $7 \mathrm{~m} \times 4.5 \mathrm{~m}$ plantation frame. The 'Orogrande' trees (13 years old), with $2.5 \mathrm{~m}$ height, $0.35 \mathrm{~m}$ trunk height, and $0.13 \mathrm{~m}$ trunk diameter, were cultivated on 


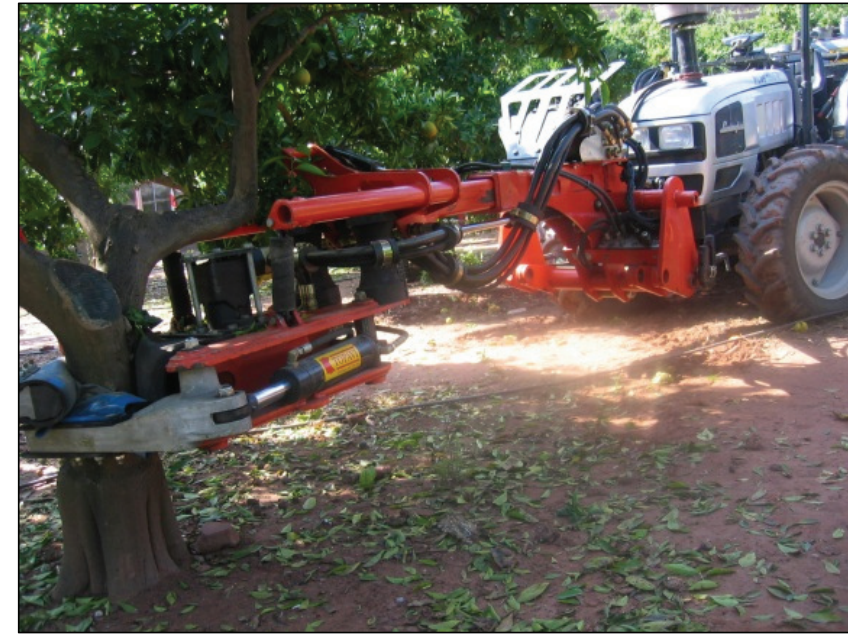

Figure 1. Tractor-mounted trunk shaker used in field experiments.

ridges and drip irrigated in a 6 to $7 \mathrm{~m} \times 2.5 \mathrm{~m}$ plantation frame. The fruits were harvested at the commercial maturity stage, with traction forces of $39.0 \pm 10.1 \mathrm{~N}$ for 'Marisol' and $65.6 \pm 20.3 \mathrm{~N}$ for 'Orogrande'. Based on the previous results of Torregrosa et al. (2009) and on preliminary tests, five 'Marisol' trees were shaken at a vibration frequency of $15 \mathrm{~Hz}$ for approximately $5 \mathrm{~s}$. Five 'Orogrande' trees were shaken with two shakes each, the first shake lasting $5 \mathrm{~s}$ and the second lasting $2 \mathrm{~s}$ and performed approximately 3 to $4 \mathrm{~s}$ after the first shake. The frequencies evaluated were $15 \mathrm{~Hz}$ in three trees and $20 \mathrm{~Hz}$ in two trees, and the displacement was $30 \mathrm{~mm}$.

The tests were performed in two orchards in a typical citrus-producing area located within a $50 \mathrm{~km}$ radius around the city of Valencia, Spain. A trunk shaker was used to harvest the mandarins, as shown in figure 1. The tractormounted trunk shaker was arranged in two parts: one part (with a mass of $640 \mathrm{~kg}$ ) was attached at the tractor's rear three-point hitch and included the oil tank and the pumps operated by the tractor's power take-off; the other part (with a mass of $730 \mathrm{~kg}$ ) was coupled to the front three-point hitch and included an extendable arm and a clamp with two moving fingers. Also included was the hydraulic motor that drives an eccentric mass of $16 \mathrm{~kg}$ with an eccentric radius of $0.13 \mathrm{~m}$ that produces an orbital vibration (Topavi light shaker, Maquinaria Agrícola Garrido s.l. (Topavi), Autol,
Spain). In all cases, the tree trunk was clamped at $200 \mathrm{~mm}$ above the ground. The tractor was a $66 \mathrm{~kW}$ four-wheel-drive model. The detachment percentage was calculated by counting and weighing the oranges removed and those remaining on the trees after being picked by hand.

To determine the removal percentage according to the vibration time, high-speed video recordings were analyzed. The cumulated number of detached fruits according to the total number of fruits was calculated and related to the vibration time.

\section{LABORATORY EXPERIMENT}

The effect of the vibration force applied to the trunk was transmitted along the tree structure. Alper et al. (1976) defined the effect of the induced frequencies and point-offorce application on the resultant amplitude at the force application zone and at the fruit suspension junction in orange trees. Gil and Torregrosa (2009) found that the tree structure strongly determines the vibration transmission and fruit detachment in mechanical lemon harvesting using a trunk shaker. Du et al. (2012), studying mechanical sweet cherry harvesting in laboratory and field tests, also reported that the energy transmission efficiency and distribution pattern were strongly related to the tree's structure, and a simply structured tree may have a greater energy transmission efficiency from the excitation point to the fruiting zones. In the Valencia region, olive trunk shakers, with low amplitude and high frequency, are being tested for mechanical fresh citrus harvesting to reduce the very high harvesting costs. Different vibration characteristics (a wider range of frequencies and amplitudes) need to be tested to improve mechanical harvesting. However, due to the low trunk height of citrus trees in the Valencia region, a commercial trunk shaker cannot be operated at intermediate and high amplitudes. To assess citrus removal percentages with vibration time at different frequencies and amplitudes based on previous results, selected branches of 'Marisol' and 'Orogrande' mandarins were tested in the laboratory.

A laboratory unidirectional vibratory device was designed to shake the citrus branches to avoid variability due to the complexity of the vibration transmission from the trunk to the branches, to reduce the error from the field data acquisition, and to study a wide range of amplitudes and frequencies (fig. 2).

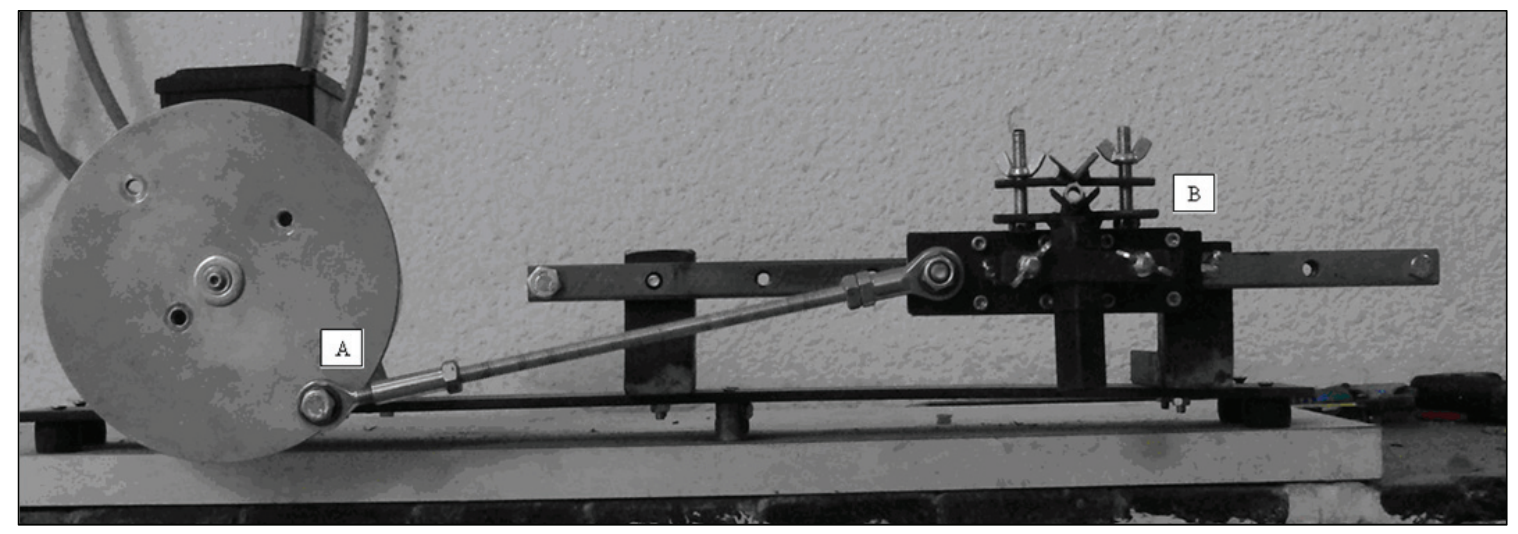

Figure 2. Laboratory unidirectional vibratory device. 
Table 1. Amplitudes, converter units, and actual frequencies according to the variety used in the tests.

\begin{tabular}{|c|c|c|c|c|c|}
\hline & & $\begin{array}{l}\text { Amplitude } \\
\text { (m) }\end{array}$ & $\begin{array}{l}\text { Converter } \\
\text { Units (ud) }\end{array}$ & $\begin{array}{c}\text { Frequency } \\
(\mathrm{Hz})\end{array}$ & $\begin{array}{l}\text { Frequency } \\
\text { Range }\end{array}$ \\
\hline \multicolumn{2}{|r|}{$\frac{\text { Variety }}{\text { 'Marisol'[a] }}$} & \multirow[t]{5}{*}{0.06} & 10 & 4.6 & Low \\
\hline & & & 15 & 7.0 & Intermediate \\
\hline & & & 20 & 9.3 & Intermediate \\
\hline & & & 30 & 14.1 & High \\
\hline & & & 40 & 18.1 & Very high \\
\hline & & \multirow[t]{3}{*}{0.10} & 10 & 4.2 & Low \\
\hline & & & 15 & 6.7 & Low \\
\hline & & & 20 & 8.8 & Intermediate \\
\hline \multirow{4}{*}{\multicolumn{2}{|c|}{${ }^{\prime}$ Orogrande $e^{,[b]}$}} & \multirow[t]{2}{*}{0.06} & 10 & 4.6 & Low \\
\hline & & & 20 & 9.3 & Intermediate \\
\hline & & \multirow[t]{2}{*}{0.140} & 10 & 3.7 & Low \\
\hline & & & 15 & 7.4 & Intermediate \\
\hline \multicolumn{6}{|c|}{$\begin{array}{l}48 \text { branches, six branches per sample, } 0.935 \mathrm{~kg} \text { per branch, } 576 \text { fruits, } \\
12.0 \text { fruits per branch, main branch diameter }=0.014 \text { to } 0.017 \mathrm{~m} \text {, } \\
\text { average traction force }(\mathrm{Ft})=39 \mathrm{~N} \text {, fruit weight }=0.079 \mathrm{~kg} \text {, and } \\
\text { maturity index }(\mathrm{MI})=5.2 \text {. }\end{array}$} \\
\hline [b] & \multicolumn{5}{|c|}{$\begin{array}{l}\text { fruits, } 8.8 \text { fruits per branch, main branch diameter }=0.014 \text { to } 0.017 \mathrm{~m} \text {, } \\
\text { average traction force }(\mathrm{Ft})=65.6 \mathrm{~N} \text {, fruit weight }=0.061 \mathrm{~kg} \text {, and } \\
\text { maturity index }(\mathrm{MI})=7.5 \text {. }\end{array}$} \\
\hline
\end{tabular}

The branches were tested in the laboratory the day after the field test was conducted and on the same day that the field samples were collected. The selected branches had a similar length, structure, and fruit distribution. Table 1 shows the average number of fruits and the average branch weight for every variety.

A connecting rod converts the rotational motion from an electric motor into linear motion to vibrate the branch. A frequency converter is used to vary the vibration frequency from 10 to 40 converter units (ud). The vibration amplitude is modified from 0.06 to $0.18 \mathrm{~m}$ by attaching the connecting rod to different holes on the disk (A in fig. 2). The branch is located in a vertical downward position (B in fig. 2).

To assess the vibration amplitude, frequency, and time relationship, the branches were vibrated for $30 \mathrm{~s}$ to obtain the highest possible removal percentage. Based on previous results, three vibration amplitudes $(0.06,0.10$, and $0.14 \mathrm{~m})$ and five converter unit frequencies $(10,15,20,30$, and 40 ud) were tested (table 1).

Video recordings of the movements were used to calculate the fruit detachment time (for the detached fruits) according to equation 1 :

$$
t_{i j}=\frac{\left(\text { photo }_{d}-\text { photo }_{0}\right)}{300}
$$

where

$$
t_{i j}=\text { time for fruit } i \text { from branch } j(\mathrm{~s})
$$

photo $_{0}=$ video frame when movement starts

photo $_{d}=$ video frame when fruit is detached.

To determine the removal percentage according to the vibration time, the cumulative number of detached fruits according to the total number of fruits was calculated by grouping all the branches vibrated with the same frequency and amplitude (simulating a tree with all the branches vibrated under the same conditions).

$$
\% \text { removal }(\mathrm{t})=\frac{\Sigma \text { detached fruits }(\mathrm{t})}{\text { Total number of fruits }}
$$

In both the field and laboratory experiments, a high-speed color video camera (Casio EXF1, www.exilim.com) was used to document the tree and branch movements at 300 frames per second (fps) and a resolution of $512 \times 384$ pixels.

The actual frequencies were measured using a triaxial accelerometer (type 8763A500, Kistler Instrument Corp., Novi, Mich., $\pm 500 \mathrm{~g}$ range, $10 \mathrm{mV} \mathrm{g}^{-1}$ sensitivity, $3.3 \mathrm{~g}$ weight, mini-cube design, $0.01 \mathrm{~m}$ length) and with highspeed video recording (counting cycle time).

\section{RESULTS}

\section{FIELD EXPERIMENT}

Figures 3 and 4 show the field removal percentage according to the cumulated vibration time for the 'Marisol' and 'Orogrande' mandarins, respectively. The removal

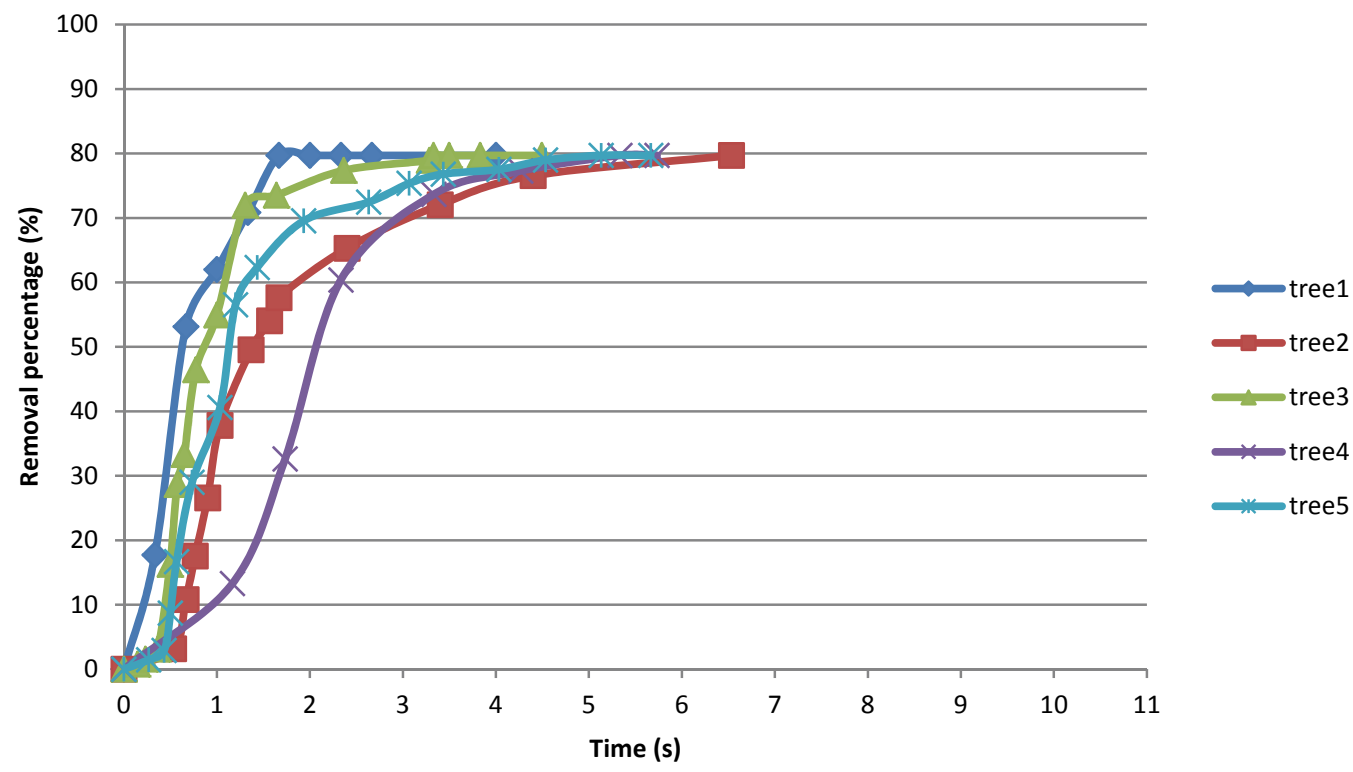

Figure 3. Field removal percentage according to cumulative vibration time for 'Marisol' mandarins at $15 \mathrm{~Hz}$ vibration frequency. 


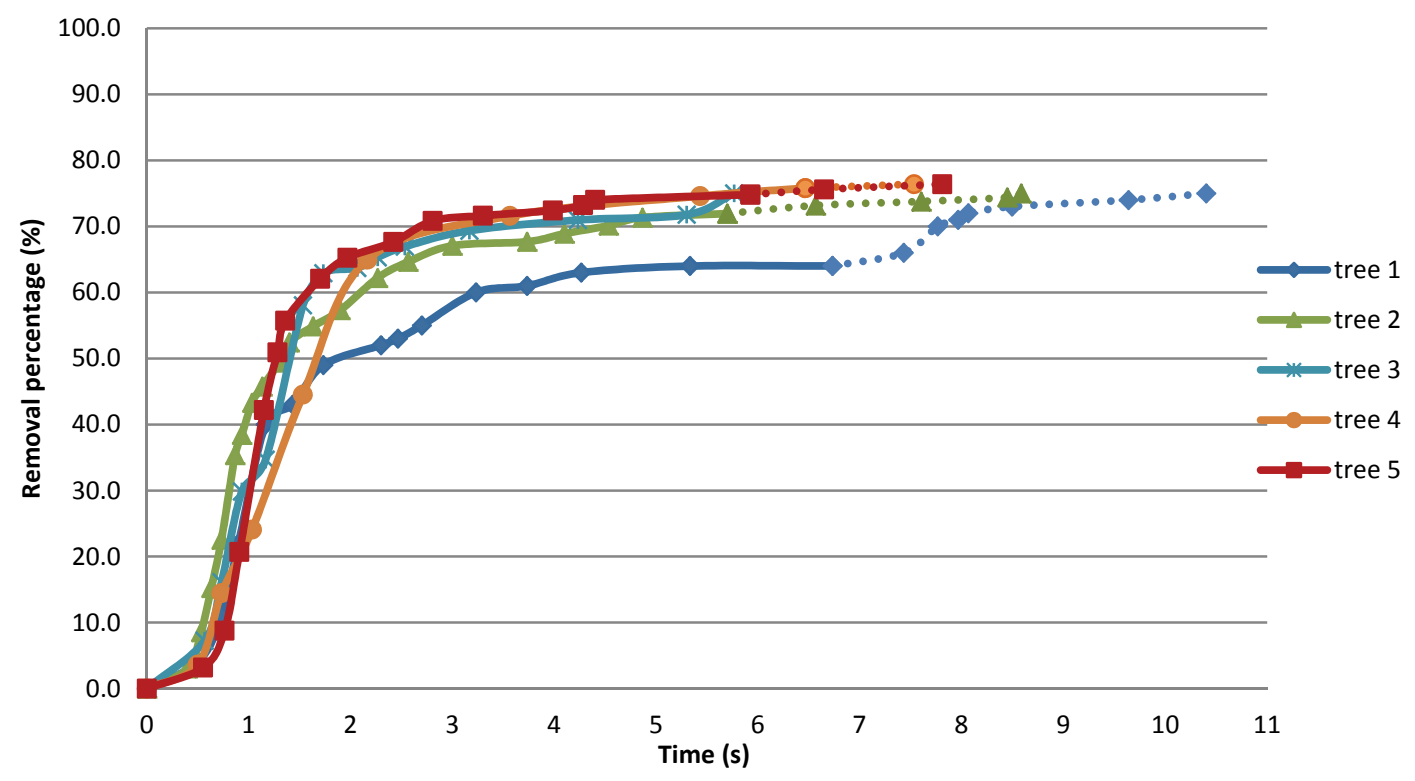

Figure 4. Field removal percentage according to cumulative vibration time for 'Orogrande' mandarins. Trees 1, 2, and 3 had a vibration frequency of $15 \mathrm{~Hz}$; trees 4 and $5 \mathrm{had}$ a vibration frequency of $20 \mathrm{~Hz}$. The discontinuous lines indicate the second vibration.

percentage follows a logarithmic behavior with vibration time, as shown in table 2 . These results confirm those of Mateev and Kostadinov (2004).

The adequate vibration time could be determined by fitting a straight line to the asymptotic part of the curve. Almost all the detached fruits fell within the first 2 to $3 \mathrm{~s}$ of shaking. Furthermore, the second shaking increased the removal percentage by less than $10 \%$ (fig. 4). These results complement those of Torregrosa et al. (2009) when affirming that two shakes of 3 to $5 \mathrm{~s}$ each are adequate to obtain an acceptable removal percentage. Moreover, Torregrosa et al. (2009) concluded that the first shake removed the highest proportion of fruits $69 \%$ of the total removed fruits in 'Salustiana' oranges) and that the removal percentages increased with the total shaking time, but the differences were not statistically significant at $5 \%$.

When vibrating for less than $5 \mathrm{~s}$ at a frequency of 15 to 20 $\mathrm{Hz}$, an acceptably low defoliation of less than $1.2 \mathrm{~kg}$ per tree was obtained.

Table 2. Logarithmic equations estimated for the two varieties in the field test removing the origin point: $y=$ removal percentage $(\%)$, and $x=$ vibration time (s).

\begin{tabular}{ccc}
\hline & $\begin{array}{c}\text { Logarithmic Equation } \\
(y=A+B \cdot \ln (x))\end{array}$ & $\begin{array}{c}\text { Adjusted } \\
\mathrm{R}^{2}\end{array}$ \\
\hline 'Marisol' (15 Hz frequency) & & \\
1 & $y=57.95+25.18 \cdot \ln (x)$ & 83.03 \\
2 & $y=31.49+32.25 \cdot \ln (x)$ & 91.45 \\
3 & $y=46.55+29.41 \cdot \ln (x)$ & 87.55 \\
4 & $y=13.39+42.33 \cdot \ln (x)$ & 89.82 \\
5 & $y=40.03+28.43 \cdot \ln (x)$ & 89.50 \\
\hline 'Orogrande' (15 Hz frequency) \\
1 \\
$y=29.07+20.92 \cdot \ln (x)$ & 91.32 \\
3 & $y=36.11+22.09 \cdot \ln (x)$ & 88.39 \\
$y=33.91+28.96 \cdot \ln (x)$ & 84.33 \\
\hline 'Orogrande' (20 Hz frequency) & \\
1 & $y=-27.68+27.84 \cdot \ln (x)$ & 92.43 \\
$y$ & $y=34.47+26.41 \cdot \ln (x)$ & 79.01 \\
\hline
\end{tabular}

\section{LABORATORY EXPERIMENT}

Figures 5 and 6 show the laboratory removal percentages according to the cumulative vibration time (for each combination of frequency and amplitude) for 'Marisol', and figure 7 shows the results for 'Orogrande'. The removal percentage depends on the vibration characteristics (frequency and amplitude) and time. For 'Marisol', the large amplitude and intermediate frequency $(0.10 \mathrm{~m}$ and $6.7 \mathrm{~Hz})$ required less than $5 \mathrm{~s}$ to achieve $70 \%$ removal and less than $10 \mathrm{~s}$ for an $80 \%$ removal. At a higher frequency $(0.10 \mathrm{~m}$ and $8.8 \mathrm{~Hz})$ the results were similar, but the final removal percentage was higher, achieving $100 \%$ removal after $20 \mathrm{~s}$. Similar results were obtained at low amplitude $(0.06 \mathrm{~m})$ and $14.1 \mathrm{~Hz}$ frequency, but more time was required to obtain $70 \%$ removal. The best results were found at low amplitude $(0.06 \mathrm{~m})$ and very high frequency $(18.1 \mathrm{~Hz})$, when $100 \%$ removal was achieved in only $5 \mathrm{~s}$. However, very high frequencies could cause damage to the tree (mainly defoliation) and increase fuel consumption. Neither high amplitude and low frequency $(0.10 \mathrm{~m}$ and $4.2 \mathrm{~Hz})$ nor low amplitude $(0.06 \mathrm{~m})$ and intermediate frequency achieved more than $60 \%$ removal.

For 'Orogrande', with the exception of branches vibrated with a large amplitude and intermediate frequency $(0.14 \mathrm{~m}$ and $7.4 \mathrm{~Hz}$ ), the removal percentage was lower than $60 \%$. Branches vibrated with a large amplitude and an intermediate frequency required $15 \mathrm{~s}$ more (from 15 to $30 \mathrm{~s}$ vibration time) to increase the removal percentage from $90 \%$ to $100 \%$.

The removal percentage and vibration time results from the laboratory experiment cannot be as accurate as those from the field experiment. However, as in the field experiment, the removal percentage followed a logarithmic behavior with vibration time. A logarithmic model was fitted for the two varieties (table 3).

To achieve high removal percentages, reduced vibration time (less fuel consumption, less time per tree, and less tree 


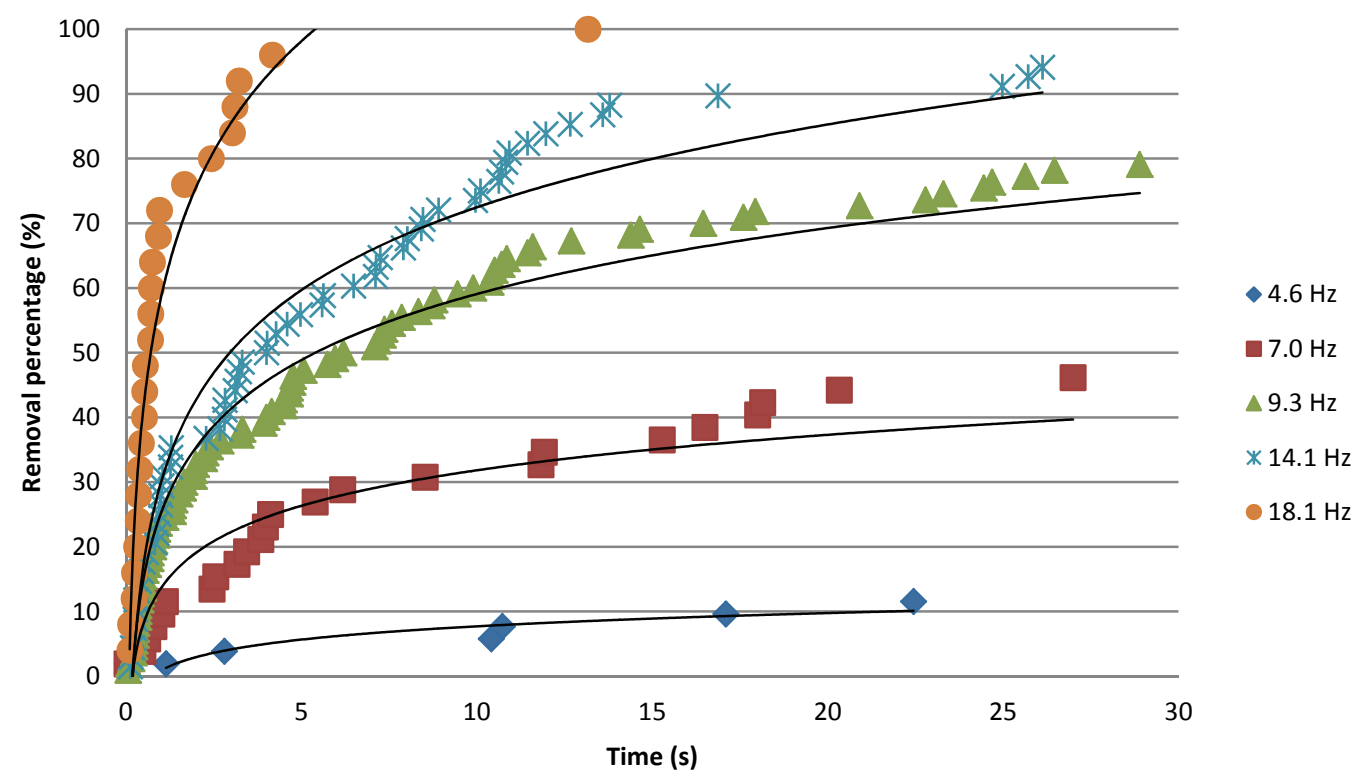

Figure 5. Laboratory removal percentage according to the cumulative vibration time for 'Marisol' mandarins vibrated at a $60 \mathrm{~mm}$ amplitude at 4.6, 7.0, 9.3, 14.1, and $18.1 \mathrm{~Hz}$.

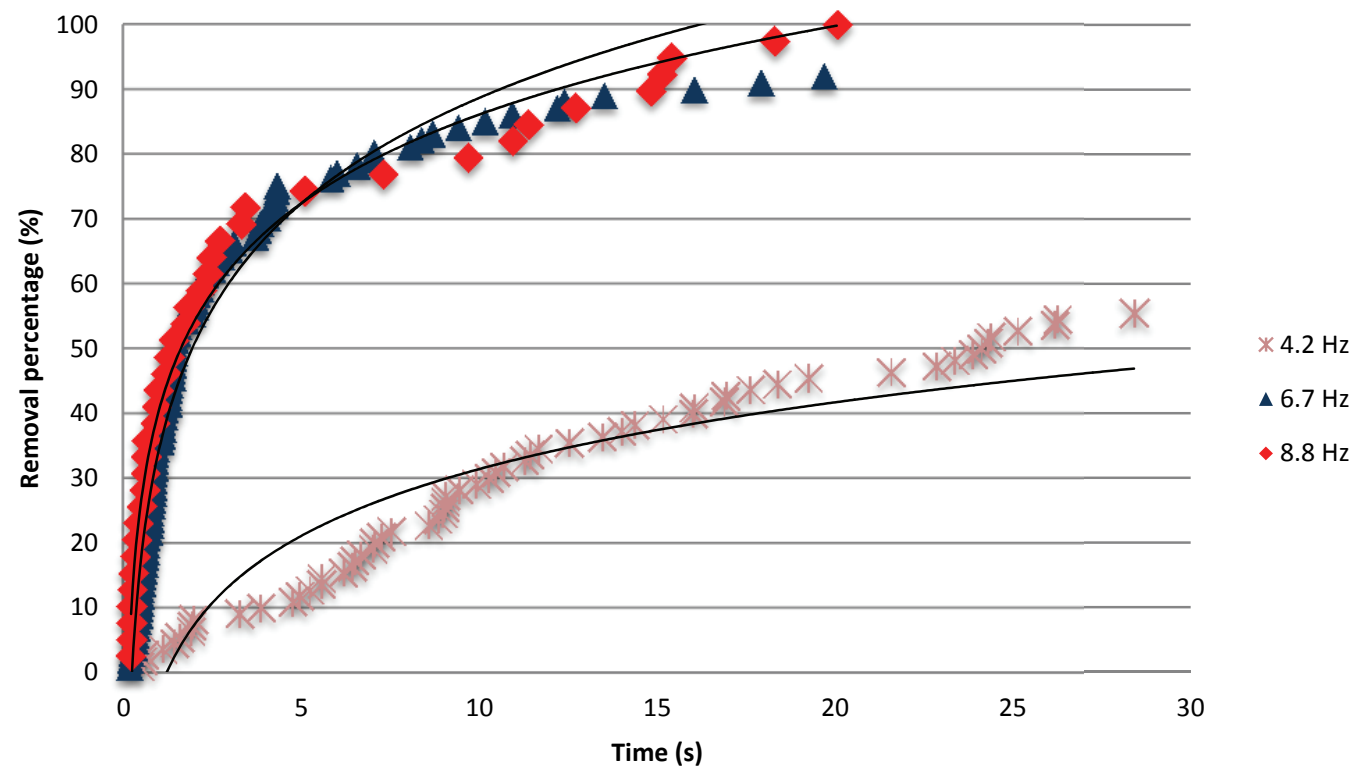

Figure 6. Laboratory removal percentage according to the cumulative vibration time for 'Marisol' mandarins vibrated at a $100 \mathrm{~mm}$ amplitude.

injury), large amplitudes, and intermediate frequencies could be used. For 'Marisol', a multiple regression test was performed to relate parameter $B$ (from the logarithmic equation $y=A+B \cdot \ln (x))$ to the variables frequency and amplitude. Parameter $B$ was positively related to frequency and amplitude (adjusted $\mathrm{R}^{2}=70.5$ ).
The detachment process can be divided into two periods. In the first period of the vibration process, the removal percentage increases rapidly as the time increases. After this period, however, a large increase in time produces a small increase in the removal percentage. The length of the first period and the maximum removal percentage depend on the frequency and the amplitude. 


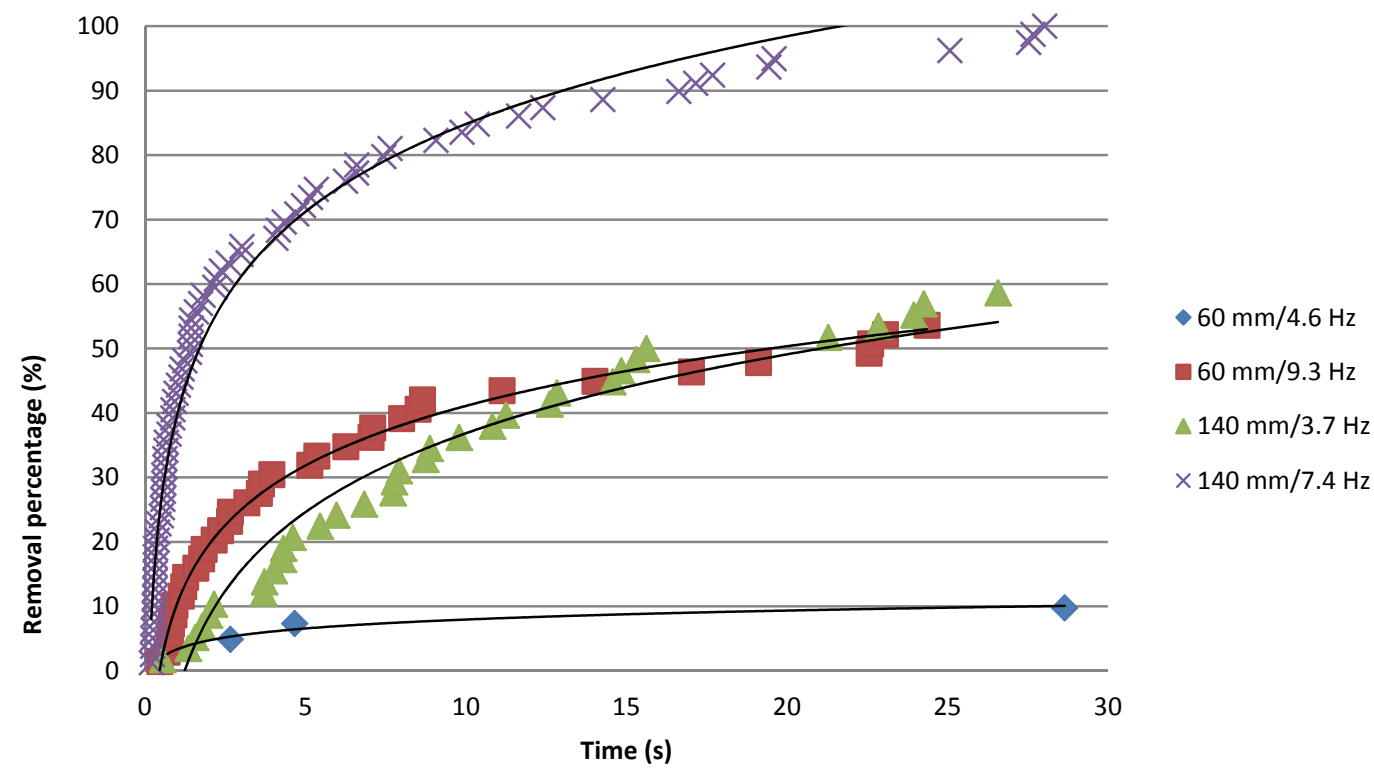

Figure 7. Laboratory removal percentage according to the cumulative vibration time for 'Orogrande' mandarins.

Table 3. Logarithmic equations estimated for the two varieties in the lab test: $y=$ removal percentage (\%), and $x=$ vibration time (s).

\begin{tabular}{ccc}
\hline $\begin{array}{c}\text { Frequency } \\
(\mathrm{Hz})\end{array}$ & $\begin{array}{c}\text { Logarithmic Equation } \\
(y=A+B \cdot \ln (x))\end{array}$ & $\begin{array}{c}\text { Adjusted } \\
\mathrm{R}^{2}\end{array}$ \\
\hline 'Marisol' (0.06 m amplitude) & & \\
4.6 & $y=0.90+2.96 \cdot \ln (x)$ & 89.39 \\
7 & $y=13.60+7.91 \cdot \ln (x)$ & 83.9 \\
9.3 & $y=25.19+14.72 \cdot \ln (x)$ & 97.17 \\
14.1 & $y=29.94+18.47 \cdot \ln (x)$ & 96.54 \\
18.1 & $y=58.50+24.63 \cdot \ln (x)$ & 92.16 \\
\hline 4.2 & $y=-2.87+14.87 \cdot \ln (x)$ & \\
6.7 & $y=34.67+23.48 \cdot \ln (x)$ & 95.46 \\
8.8 & $y=40.72+19.73 \cdot \ln (x)$ & 98.43 \\
\hline 'Marisol' (0.10 m amplitude) & \\
4.6 & $y=3.33+2.01 \cdot \ln (x)$ & 94.44 \\
9.3 & $y=10.34+13.36 \cdot \ln (x)$ & 99.35 \\
\hline 'Orogrande' $(0.06$ m amplitude) \\
'Orogrande' $(0.14$ m amplitude) \\
3.7 & $y=-3.82+17.66 \cdot \ln (x)$ \\
7.4 & $y=39.62+19.63 \cdot \ln (x)$ & 93.59 \\
&
\end{tabular}

\section{CONCLUSION}

Field results showed that the mechanical citrus removal percentage exhibits a logarithmic behavior with time. This result was confirmed in laboratory tests using a unidirectional vibratory device. Lengthening the shaking times and repeating the shaking process did not increase removal efficiency. Almost all the detached fruit fell in the first 2 to $3 \mathrm{~s}$ of shaking. It was evident that two shakes were not necessary to obtain an acceptable removal percentage. For the varieties and conditions studied, a single shake of $15 \mathrm{~Hz}$ for 2 to $3 \mathrm{~s}$ could be adequate to obtain an acceptable removal percentage for fresh mandarin growers in the Valencia region (approximately $70 \%$, according to García, 2011). Moreover, after a vibration of 2 to $3 \mathrm{~s}$ with a frequency lower than $20 \mathrm{~Hz}$, very low defoliation was produced (less than $1.2 \mathrm{~kg}$ per tree).

The removal percentage depends on the amplitude, frequency, and vibration time. Laboratory tests of branch shaking showed that large amplitudes and low frequencies ( 0.10 to $0.14 \mathrm{~m}$ and less than $5 \mathrm{~Hz}$ ) and low amplitudes and intermediate frequencies $(0.06 \mathrm{~m}$ and more than $7 \mathrm{~Hz})$ did not achieve a removal percentage greater than $60 \%$. Large amplitudes and intermediate frequencies $(0.10$ to $0.14 \mathrm{~m}$ and 7 to $8 \mathrm{~Hz}$ ) could be used to achieve high citrus removal percentages and to reduce vibration time per tree. This result agrees with those found in field tests by Whitney et al. (2000), who maintained that low and intermediate frequencies $(6$ to $10 \mathrm{~Hz}$ ) with $0.05 \mathrm{~m}$ amplitude had a $15 \%$ higher removal percentage than high and very high frequencies (15 to $18 \mathrm{~Hz})$ with lower displacement $(0.03 \mathrm{~m})$. These laboratory results indicate the possibility of reducing the frequencies and increasing the amplitudes to achieve optimal mechanical citrus harvesting. For harvesting fresh market citrus in the Mediterranean area, with a low citrus trunk height, mechanical equipment could be adapted to achieve large vibration amplitudes and intermediate vibration frequencies in the branches.

The removal percentage change follows a logarithmic behavior with the vibration time. More energetic combinations of frequency and amplitude have a higher slope in the first vibration period and a higher asymptotic final removal percentage. In the first period of the vibration process, the removal percentage increases rapidly with time. After this period, however, there is a ceiling effect on the removal percentage, and a large increase of time yields a small increase in the removal percentage. To achieve high removal percentages while reducing the vibration time, the logarithmic behavior of the vibration process and the duration of the first period need to be taken into account when performing mechanical citrus harvesting. To reduce fuel consumption, increase the life of the equipment, and reduce the risk of damage to the tree, the vibration time should not be greater than the first period of time. 


\section{ACKNOWLEDGEMENTS}

This study was funded by the Ministerio de Ciencia e Innovación (research project RTA2009-00118-C02-02) and FEDER. The authors are most grateful to Agricultural Engineering Pablo Escuin Garin.

\section{REFERENCES}

Alper, Y., A. Foux, and U. M. Peiper. 1976. Experimental investigation of orange tree dynamics under mechanical shaking. J. Agric. Eng. Res. 21(11): 121-131

Blanco-Roldan, G. L., J. A. Gil-Ribes, K. Kouraba, and S. CastroGarcía. 2009. Effects of trunk shaker duration and repetitions on removal efficiency for the harvesting of oil olives. Applied Eng. in Agric. 25(3): 329-334.

Brown, G. K. 2005. New mechanical harvesters for the Florida citrus juice industry. HortTech. 15(1): 69-72.

Du, X., D. Chen, Q. Zhang, P. A. Scharf, and M. D. Whitting. 2012. Dynamic responses of sweet cherry trees under vibratory excitations. Biosyst. Eng. 111(3): 305-314.

García, O. 2011. Estudio de costes de la recolección de naranjas por vibrador de troncos mediante análisis de sensibilidad. Trabajo Final de Carrera. Valencia, Spain: Universidad Politécnica de Valencia, Instituto Valenciano de Investigaciones Agrarias.

Gil, J., and A. Torregrosa. 2009. Análisis de la vibración producida en limones por un vibrador de tronco y su efecto sobre el desprendimiento de limones. In Proc. V Congreso Nacional y II Congreso Ibérico de Agroingeniería. Lugo, Spain: Escuela Politécnica Superior.

He, L., J. Zhou, P. A. Scharf, and Q. Zhang. 2012. Energy efficiency analysis of a mechanical shaker for sweet cherry harvest. Proc.
Intl. Symp. Mechanical Harvesting and Handling of Fruits and Nuts. Gainesville, Fla.: University of Florida, IFAS.

Hedden, S. C., D. B. Churchill, and J. D. Whitney. 1988. Trunk shakers for citrus harvesting: Tree growth, fruit yield, and removal. Applied Eng. in Agric. 4(2): 102-106.

Li, K., and J. P. Syvertsen. 2005. Mechanical harvesting has little effect on water status and leaf gas exchange in citrus trees. $J$. American Soc. for Hort. Sci. 130(5): 661-666.

Mateev, L. M., and G. D. Kostadinov. 2004. Probabilistic model of fruit removal during vibratory morello harvesting. Biosyst. Eng. 87(4): 425-435.

Ortiz, C., J. Blasco, S. Balasch, and A. Torregrosa. 2011. Shockabsorbing reception surfaces for collecting fruit during the mechanical harvesting of citrus. Biosyst. Eng. 110(1): 2-5.

Peterson, D. L. 1998. Mechanical harvester for process orange. Applied Eng. in Agric. 14(5): 455-458.

Reig-Martinez, E., and A. J. Picazo-Toledo. 2004. Analysing farming systems with data envelopment analysis: Citrus farming in Spain. Agric. Systems 82(1): 17-30.

Roka, F. M., J. K. Burns, and R. S. Buker. 2005. Mechanical harvesting without abscission agents: Yield impacts on late season 'Valencia' oranges. Proc. Florida State Hort. Soc. 118: 25-27.

Torregrosa, A., E. Ortí, B. Martín, J. Gil, and C. Ortiz. 2009. Mechanical harvesting of oranges and mandarins in Spain. Biosyst. Eng. 104(1): 18-24.

Torregrosa, A., I. Porras, and B. Martín. 2010. Mechanical harvesting of lemons (cv. Fino) in Spain using abscission agents. Trans. ASABE 53(3): 703-708.

Whitney, J. D., V. Hartmond, W. J. Kender, J. K. Burns, and M. Salyani. 2000. Orange removal with trunk shakers and abscission chemicals. Applied Eng. in Agric. 16(4): 367-371. 